\title{
BMJ Open Personal preferences for Personalised Trials among patients with chronic diseases: an empirical Bayesian analysis of a conjoint survey
}

\author{
Ying Kuen Cheung (D , ${ }^{1}$ Dallas Wood, ${ }^{2}$ Kangkang Zhang, ${ }^{1}$ Ty A Ridenour, ${ }^{2}$ \\ Lilly Derby, ${ }^{3}$ Tara St Onge, ${ }^{3}$ Naihua Duan, ${ }^{1}$ Joan Duer-Hefele, ${ }^{4}$ Karina W Davidson, ${ }^{4}$ \\ Ian Kronish (D), ${ }^{3}$ Nathalie Moise ${ }^{3}$
}

To cite: Cheung YK, Wood D Zhang K, et al. Personal preferences for Personalised Trials among patients with chronic diseases: an empirical Bayesian analysis of a conjoint survey. BMJ Open 2020;10:e036056. doi:10.1136/ bmjopen-2019-036056

- Prepublication history and additional material for this paper are available online. To view these files, please visit the journal online (http://dx.doi. org/10.1136/bmjopen-2019036056).

Received 06 December 2019

Revised 05 May 2020

Accepted 06 May 2020

Check for updates

(c) Author(s) (or their employer(s)) 2020. Re-use permitted under CC BY-NC. No commercial re-use. See rights and permissions. Published by BMJ.

${ }^{1}$ Biostatistics, Columbia University Irving Medical Center, New York, New York, USA ${ }^{2}$ RTI International, Research Triangle Park, North Carolina, USA

${ }^{3}$ Center Behavioral Cardiovascular Health, Columbia University Irving Medical Center, New York, New York, USA

${ }^{4}$ Research, Feinstein Institute for Medical Research, Manhasset, New York, USA

Correspondence to Dr Ying Kuen Cheung; yc632@cumc.columbia.edu

\section{ABSTRACT}

Objective To describe individual patient preferences for Personalised Trials and to identify factors and conditions associated with patient preferences.

Design Each participant was presented with 18 conjoint questions via an online survey. Each question provided two choices of Personalised Trials that were defined by up to eight attributes, including treatment types, clinician involvement, study logistics and trial burden on a patient.

Setting Online survey of adults with at least two common chronic conditions in the USA.

Participants A nationally representative sample of 501 individuals were recruited from the Chronic Illness Panel by Harris Poll Online. Participants were recruited from several sources, including emails, social media and telephone recruitment of the target population.

Main outcome measures The choice of Personalised Trial design that the participant preferred with each conjoint question.

Results There was large variability in participants' preferences for the design of Personalised Trials. On average, they preferred certain attributes, such as a short time commitment and no cost. Notably, a population-level analysis correctly predicted $62 \%$ of the conjoint responses. An empirical Bayesian analysis of the conjoint data, which supported the estimation of individual-level preferences, improved the accuracy to $86 \%$. Based on estimates of individual-level preferences, patients with chronic pain preferred a long study duration $(p \leq 0.001)$. Asthma patients were less averse to participation burden in terms of datacollection frequency than patients with other conditions $(p=0.002)$. Patients with hypertension were more costsensitive $(p<0.001)$.

Conclusion These analyses provide a framework for elucidating individual-level preferences when implementing novel patient-centred interventions. The data showed that patient preference in Personalised Trials is highly variable, suggesting that individual differences must be accounted for when marketing Personalised Trials. These results have implications for advancing precise interventions in Personalised Trials by indicating when rigorous scientific principles, such as frequent monitoring, is feasible in a substantial subset of patients.
Strengths and limitations of this study

- This large online conjoint survey leveraged a rigorously assembled panel by Harris Poll Online.

- We surveyed a nationally representative sample for age, gender, race/ethnicity, socioeconomic status and geography in the USA.

- The individual-level analyses took advantage of an empirical Bayesian procedure that borrowed information from across individuals.

- Utilities in conjoint analysis are interpreted relatively among the attributes included in the survey, and cannot be interpreted in any absolute sense.

- Generalisability of our findings might be limited to patients with two or more chronic conditions predefined in the study.

\section{INTRODUCTION}

When managing chronic diseases and conditions, patients commonly try different treatments over time before finding the 'right' treatments for them. Personalised Trials, also known as N-of-1 trials, aim to facilitate this type of patient-centred experimentation. Contrast to the conventional randomised clinical trials where each participant is randomised once to a single treatment, Personalised Trials randomise treatments to the patient in multiple crossover periods using clinical trial principles, such as blinding and ascertaining ecological outcomes. ${ }^{12}$ These methods are particularly suitable for identifying long-term treatments for chronic conditions for which treatment effects are heterogeneous across patients and thus require individualised treatments. ${ }^{3}$ In a series of demonstration trials, Personalised Trials led to valuable changes in treatment, cessation of treatment or confirmation of the original treatment. ${ }^{4-8}$ Due to its pragmatic nature, the practice of Personalised Trials may provide individual patients 
with the best evidence about their treatment choices. As a result, some have placed Personalised Trials at the top of the methodological hierarchy of evidence-based medicine for informing treatment decisions. ${ }^{4}$ Recently, there has been renewed interest in using Personalised Trials for a variety of conditions, ${ }^{9-12}$ however, their clinical practice remains scattered due, in part, to insufficient patient acceptability and demand. ${ }^{13-15}$

With a goal of increasing the adoption of Personalised Trials into clinical practice, we developed a 'collaboratory' comprising a diverse pool of stakeholders-including patients-relevant to the design and implementation of Personalised Trials. ${ }^{16}$ Under the guidance of the collaboratory, we conducted an online conjoint survey in a representative sample of adults with chronic conditions who reside in the USA. In a primary analysis, which ascertained patient preferences for the design of Personalised Trials, we identified significantly positive utilities for Personalised Trials that would impose no out-of-pocket costs on patients and for those that would require a short time commitment for daily self-tracking. ${ }^{17}$ These findings generally reflect that the average patient prefers Personalised Trials that are less burdensome in terms of cost and time commitment. They also provide useful information on design acceptability on a population level. However, the degree to which individual-level preferences are driving acceptability of Personalised Trials remains unknown.

Conjoint surveys are a well-established method for assessing product acceptability in market research and economics, and more recently, for assessing patient preferences in healthcare at the population level. ${ }^{18-22}$ Recent interest in precision medicine has increased the focus on elucidating patient preferences at both the population and individual levels. While heterogeneity of treatment effects in the population motivates Personalised Trials, heterogeneity in individual preferences of attributes for Personalised Trials may be critical to explaining acceptability and improving dissemination of this approach. In this article, we used the full conjoint data to assess variations in individual-level preferences for the design of Personalised Trials and to identify subpopulations of patients according to their preferences.

\section{METHODS}

\section{Survey development}

We designed an online survey study by engaging stakeholders through a Personalised Trial collaboratory. This collaboratory consisted of 30 members, including patients with multiple comorbidities, clinicians with and without experience conducting N-of-1 trials, healthcare administrators, scientists, methodologists/statisticians, ethicists and experts in dissemination. Between July 2014 to September 2017, the collaboratory met quarterly to review the study design, conduct, analysis and dissemination/interpretability. Collaboratory meetings were conducted by phone and in person, and they were scheduled to maximise the availability of all participants. This

\begin{tabular}{|c|c|c|}
\hline Domain & $\begin{array}{l}\text { Design } \\
\text { attributes }\end{array}$ & Levels \\
\hline \multirow[t]{2}{*}{$\begin{array}{l}\text { Clinician } \\
\text { involvement }\end{array}$} & $\begin{array}{l}\text { Treatment } \\
\text { selection }\end{array}$ & $\begin{array}{l}\text { Patient chooses } \\
\text { treatments to compare } \\
\text { in the study } \\
\text { Clinician chooses } \\
\text { treatments to compare } \\
\text { in the study }\end{array}$ \\
\hline & Trial conduct & $\begin{array}{l}\text { Study is conducted } \\
\text { without clinician } \\
\text { involvement } \\
\text { Study is conducted } \\
\text { with clinician } \\
\text { involvement }\end{array}$ \\
\hline Treatment & $\begin{array}{l}\text { Type of } \\
\text { treatment }\end{array}$ & $\begin{array}{l}\text { Prescription medication } \\
\text { Lifestyle change } \\
\text { Complementary } \\
\text { alternative medicine }\end{array}$ \\
\hline \multirow[t]{3}{*}{$\begin{array}{l}\text { Burden of } \\
\text { participation }\end{array}$} & $\begin{array}{l}\text { Time } \\
\text { commitment }\end{array}$ & $\begin{array}{l}-5 \text { min per day } \\
30 \text { min per day }\end{array}$ \\
\hline & $\begin{array}{l}\text { Data collection } \\
\text { frequency }\end{array}$ & $\begin{array}{l}\text { Once per day } \\
\text { Three times per day }\end{array}$ \\
\hline & Study duration & $\begin{array}{l}2 \text { weeks } \\
-12 \text { weeks }\end{array}$ \\
\hline Patient burden & $\begin{array}{l}\text { Out-of-pocket } \\
\text { cost }\end{array}$ & $\begin{array}{l}\text { No cost (all costs, } \\
\text { including travel, are } \\
\text { covered) } \\
\text { US } \$ 100\end{array}$ \\
\hline Logistics & Blinding & $\begin{array}{l}\text { The study is not blinded } \\
\text { The study is blinded }\end{array}$ \\
\hline
\end{tabular}

approach fostered a transparent process and helped to improve the relevance of the study question. To inform survey development, we first conducted focus groups with providers $(n=24)$ and patients $(n=54)$ to understand attitudes toward Personalised Trials and design features. ${ }^{23} 24$ We then conducted an initial survey and literature review to identify the key design attributes that could be informed by patient preferences (eg, blinding, intensity of self-tracking, extent of clinician involvement).

As part of a second survey, each participant answered 18 choice-based conjoint questions that simulated the selection of a Personalised Trial. Each question prompted participants to select which prototype they preferred in two hypothetical trial prototypes with up to eight design attributes (table 1). Of the 18 conjoint questions, 15 used a short format in which participants chose between two hypothetical trials that differed by only two attributes (eg, no-cost and long-duration trial vs some-cost and lowduration trial) (figure 1). The remaining three conjoint questions used a long format in which participants chose between two hypothetical trials that differed across all eight attributes at once (figure 2). We tested for interactions between attributes in our previous work, considering only data from the three long-format questions, and 


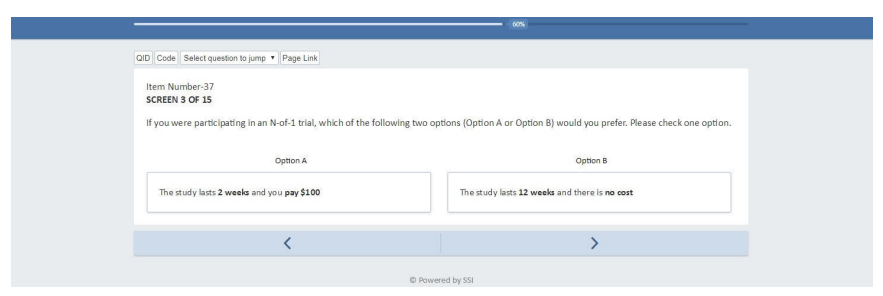

Figure 1 Example of a short-format question shown to a participant in the online survey. This screenshot presents two attributes (study duration and cost) in each of the two hypothetical trials (option A and option B).

we did not find any evidence. ${ }^{17}$ In the present analysis, in which we were interested in identifying individual-level preferences, we used data from all 18 questions per individual. We developed a statistically efficient design using Sawtooth Choice-Based Conjoint software (Sawtooth, 2010 ) to generate a pool of 60 conjoint questions (45 short and 15 long). For the short questions, each attribute appeared with other attributes in the same question at least once to allow for direct contrast. The method for generating the long-format questions was similar to that previously reported. ${ }^{17}$ In all, each participant was randomly assigned 18 conjoint questions, 15 of which were drawn from the 45 short questions and 3 from the 15 long questions. In addition to conjoint questions, we collected data on the survey participants' demographics and diagnosis of chronic disease. The survey used in the study is provided in online supplementary file 1 .

\section{Patient public involvement}

Fifty-four patients were involved in the development of the initial survey through the collaboratory and focus groups. This process helped informed how we defined the parameters in the conjoint survey.

\section{Study participants}

We conducted the survey among 501 participants who were at least 18 years old, resided in the USA and reported

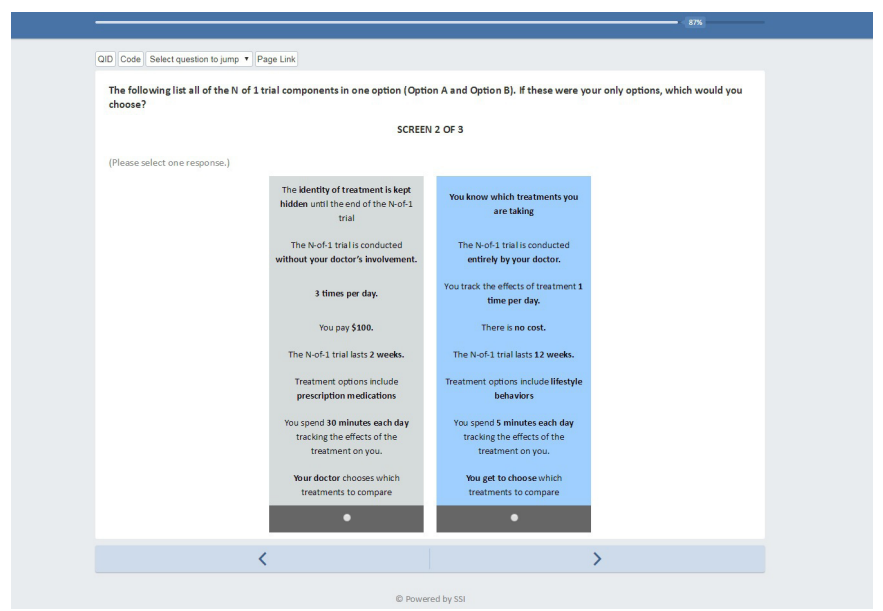

Figure 2 Example of a long-format question shown to a participant in the online survey. This screenshot presents eight attributes in each of the two hypothetical trials (option A and option B). having two or more chronic diseases from a list of six diseases (asthma, osteoporosis, depression, diabetes, hypertension and hyperlipidaemia). This eligibility list of diseases reflected a mix of symptomatic, asymptomatic and mental health conditions that are among the most highly prevalent and burdensome in the USA. ${ }^{25} 26$ Recruitment of the participants was achieved through a general population panel maintained by Harris Poll Online (HPOL), which includes several million online members. The HPOL panel was recruited from several sources, including targeted emails sent by online partners, social media, news and telephone recruitment of targeted populations. Each recruitment source was carefully vetted through a rigorous interviewing and testing process and then continually monitored for response quality. For the present study, the HPOL database of respondent information was actively screened and updated along with numerous demographic and psychographic variables to allow for precision in the online sample provided. These sampling procedures have been widely used and support a rigorous, scientifically acceptable practice without spending considerable time and energy assembling large, comprehensive samples. ${ }^{27}$ To reach the target sample size and achieve a representative sample with at least two chronic diseases ${ }^{28}$ we screened and invited 15883 potentially eligible individuals from the HPOL to participate in the study via email. Details about sample size determination and participant inclusion were reported previously. ${ }^{17}$ All participants provided informed consent via e-signature. Only those participants at least minimally interested in participating in a Personalised Trial for hypertension, hyperlipidaemia, diabetes, depression, arthritis/joint pain, breathing problems/bronchitis/asthma, back pain or sleeping problems/insomnia completed the survey. These patient conditions were the highest-ranked, patient-preferred conditions and deemed appropriate for Personalised Trials in our prior research. The cohort selection and participant characteristics are described in a previous report. ${ }^{17}$

\section{Statistical analysis}

Estimating individual-level utilities and preferences

Individual patient preferences for different attributes of Personalised Trials were estimated using empirical Bayesian latent utility modelling on all conjoint responses of the participants. Details of the model are given in online supplementary file 2. Briefly, under this model, the latent utility of trial prototype $j$ to a participant $i$ (denoted as $u_{i j}$ ) was postulated to follow a logistic distribution in which the mean depended on a linear combination of trial attributes. Specifically, having $u_{i j}=\beta_{i}^{T} x_{i j}+\varepsilon_{i j}$, where $\varepsilon_{i j}$ is a standard logistic error and the design $x_{i j}$ indicated the presence/absence of attributes in prototype $j$ presented to the participant. The coefficient $\beta_{i}$ captured the individual-level utility of participant $i$ and was estimated by the posterior mode assuming a mean zero normal prior on $\beta_{i}$. We circumvented the subjectivity of postulating the prior variance-covariance matrix by estimating 
the matrix empirically using the marginal likelihood. ${ }^{29}$ For each attribute, a participant was indicated to have a positive or negative preference if the estimated individual utility was positive or negative, respectively. The reliability of the estimate for individual-level utilities depended on the number of questions answered per participant. Thus, we excluded from the analysis those who answered 16 or fewer of the 18 questions.

In addition, we fitted a latent utility model at a population level to all conjoint responses. This model assumed no individual deviations from the population average and set $\beta_{i}=\beta$ for all participants. Under this population model, every individual would be estimated to have the same preference for a given attribute.

The benefits of accounting for individual preferences were assessed by comparing the classification rates of correct responses in the personalised and populationlevel models. Correlations among the design attributes were explored graphically and using Pearson correlation coefficients based on the individual-level utilities estimated by the personalised model.

\section{Sample segmentation}

We recorded the following baseline characteristics for each participant and summarised them as categorical variables: age (younger than 65 years vs 65 years or older), sex (male vs female), race/ethnicity (non-Hispanic white vs others), income (less than US\$35000 vs US $\$ 35000$ or more), education (some college or more vs less than college), work status (employed full-time/part-time vs not employed), insurance status (with vs without insurance) and region of residence (Northeast vs South vs Midwest vs West). Associations between these characteristics and individual preferences were summarised using contingency tables and tested using $\chi^{2}$ tests; two-sided $p$ values were reported. As exploratory analyses, we also compared the variability of individual-level utilities by these characteristics using Bartlett's test, and we displayed the utility distributions in graphs.

We also considered the following chronic conditions in the analysis: joint pain, asthma, back pain, depression, diabetes, hypertension, hyperlipidaemia and insomnia. We asked whether a participant had a given condition; those who had the condition were asked to indicate their interest in participating in Personalised Trials. Association between chronic conditions and individual preferences were analysed in the same manner as above.

\section{RESULTS}

\section{Population-level utilities}

Among the 501 survey participants, most $(n=497)$ answered all 18 conjoint questions and three answered 17 questions (14 short-format, 3 long-format). One participant who answered all 15 short questions but not the long questions was excluded from the analysis. Thus, we estimated the utilities in 500 participants with a total of 8997 conjoint responses (1500 long-format and 7497

\begin{tabular}{|c|c|c|c|}
\hline Characteristics & $\mathrm{N}(\%)$ & Conditions & $\mathrm{N}(\%)$ \\
\hline Age & & Joint pain & \\
\hline 65 or above & $182(36 \%)$ & Yes & $215(43 \%)$ \\
\hline Below 65 & 318 (64\%) & No & 285 (57\%) \\
\hline Sex & & Asthma & \\
\hline Male & $222(44 \%)$ & Yes & 149 (30\%) \\
\hline Female & 278 (56\%) & No & $351(70 \%)$ \\
\hline Race/ethnicity & & Back pain & \\
\hline $\begin{array}{l}\text { Non-Hispanic } \\
\text { whites }\end{array}$ & 341 (68\%) & Yes & 177 (35\%) \\
\hline Others & $159(32 \%)$ & No & $323(65 \%)$ \\
\hline Education & & Depression & \\
\hline $\begin{array}{l}\text { College or } \\
\text { more }\end{array}$ & $400(80 \%)$ & Yes & $210(42 \%)$ \\
\hline $\begin{array}{l}\text { Less than } \\
\text { college }\end{array}$ & $100(20 \%)$ & No & $290(58 \%)$ \\
\hline Work status & & Diabetes & \\
\hline $\begin{array}{l}\text { Employed } \\
\text { (full-time/ } \\
\text { part-time) }\end{array}$ & $230(46 \%)$ & Yes & $180(36 \%)$ \\
\hline Not employed & 270 (54\%) & No & $320(64 \%)$ \\
\hline Income & & Hypertension & \\
\hline $\begin{array}{l}\text { US } \$ 35000 \text { or } \\
\text { above }\end{array}$ & 309 (62\%) & Yes & $371(74 \%)$ \\
\hline $\begin{array}{l}\text { Below } \\
\text { US } \$ 35000\end{array}$ & 191 (38\%) & No & $129(26 \%)$ \\
\hline Insurance & & Hyperlipidaemia & \\
\hline $\begin{array}{l}\text { Have } \\
\text { insurance }\end{array}$ & 452 (90\%) & Yes & $270(54 \%)$ \\
\hline No insurance & $48(10 \%)$ & No & $230(46 \%)$ \\
\hline Region & & Insomnia & \\
\hline Northeast & $86(17 \%)$ & Yes & $121(24 \%)$ \\
\hline South & 194 (39\%) & No & $379(76 \%)$ \\
\hline Midwest & $116(23 \%)$ & & \\
\hline West & $104(21 \%)$ & & \\
\hline
\end{tabular}

short-format) from the participants recruited through HPOL. Table 2 describes the participant characteristics and gives the distribution of the chronic conditions.

Table 3 presents the estimated utilities of trial design attributes according to the population-level model, along with the 95\% CIs. The analysis that used only the longformat questions identified two statistically significant attributes preferred by the participants on a population level: requiring short $(5 \mathrm{~min})$ time commitment (utility difference $=0.16 ; \mathrm{p}=0.015$ ) and having no cost (utility difference $=1.52 ; \mathrm{p}<0.001)$. The analysis using all conjoint questions confirmed the findings for these two attributes with greater precision. It also revealed that participants preferred complementary alternative medicine (CAM) over prescription medication (utility difference $=0.15$; 


\begin{tabular}{|c|c|c|}
\hline \multirow[b]{2}{*}{ Attribute description } & \multicolumn{2}{|c|}{ Utility $(95 \%$ Cl) } \\
\hline & $\begin{array}{l}\text { Long-format questions only } \\
(n=1500)\end{array}$ & $\begin{array}{l}\text { All questions } \\
(n=8997)\end{array}$ \\
\hline Study is conducted with clinician involvement instead of without & $0.11(-0.02$ to 0.25$)$ & $0.17(0.09 \text { to } 0.25)^{\star}$ \\
\hline Treatment is lifestyle change instead of prescription medication & $0.02(-0.17$ to 0.21$)$ & $-0.14(-0.24 \text { to }-0.05)^{*}$ \\
\hline Study collects data one time per day instead of three times per day & $0.08(-0.06$ to 0.21$)$ & $0.34(0.25 \text { to } 0.42)^{\star}$ \\
\hline Study lasts $\underline{2}$ weeks instead of 12 weeks & $0.05(-0.09$ to 0.18$)$ & $0.00(-0.09$ to 0.09$)$ \\
\hline Study has no cost instead of costing US $\$ 100$ & $1.52(1.39 \text { to } 1.66)^{\star}$ & $1.40(1.30 \text { to } 1.50)^{\star}$ \\
\hline Study is blinded instead of not being blinded & $-0.08(-0.22$ to 0.05$)$ & $-0.34(-0.42 \text { to }-0.25)^{*}$ \\
\hline
\end{tabular}

${ }^{*} \mathrm{P}<0.05$, indicated by $95 \%$ Cls excluding zero.

CAM, complementary alternative medicine.

$\mathrm{p}=0.001$ ), which was preferred over lifestyle changes (utility difference $=0.14 ; \mathrm{p}=0.002$ ), and to have clinician involvement (vs no involvement) during the study (utility difference $=0.17 ; \mathrm{p}<0.001$ ). We also found that a low frequency of data collection had a positive utility (utility difference $=0.34 ; \mathrm{p}<0.001$ ) and blinding had a negative utility (utility difference $=-0.34 ; \mathrm{p}<0.001$ ).

In summary, the population-level analysis depicted that participants favoured Personalised Trials with an experiment of CAM and clinician supervision in an unblinded fashion. They also preferred a low level of burden in terms of time commitment and data-collection frequency, as well as no out-of-pocket cost. Using this typified protocol would yield a $62 \%$ correct prediction in all 8997 conjoint responses, while randomly guessing a response would yield $50 \%$.

\section{Individual-level utilities}

Several participants had preferences that deviated from the population results shown above. Twelve per cent $(n=59)$ of the participants preferred bearing out-ofpocket costs, $18 \% \quad(\mathrm{n}=91)$ preferred a long daily time commitment and $16 \%(\mathrm{n}=78)$ preferred a frequent datacollection schedule (table 4). The cohort's average preference was skewed towards not being blinded during a trial, although to a lesser extent (30\% preferred blinding). The preferences for the other design attributes (eg, study duration) were relatively evenly distributed, suggesting heterogeneity in preferences among the participants.

Figure 3 demonstrates the variations in the numerical individual-level utilities for design attributes according to the personalised model. For example, while most participants had a strong positive preference for no cost (ie, having a positive utility vs US $\$ 100$ cost), some individuals had large negative utility for bearing no cost. Similarly, while the whole population had a negative utility on blinding, some individuals had positive utilities for blinding.
Using these estimated individual-level utilities based on the personalised model to predict responses in the conjoint survey would yield an $86 \%$ correct prediction in all 8997 responses. This result is a marked increase of 24 percentage points above the population-level analysis.

There was a strong correlation between utilities for clinician involvement during a study and a clinician choosing the treatments when planning the study (correlation $=0.96 ; \mathrm{p}<0.001$; figure $4 \mathrm{~A})$. Attributes related to burden of participation were correlated: participants who had high utilities for short daily time commitment tended to have high utilities for fewer data collections per day (correlation $=0.87 ; \mathrm{p}<0.001$; figure $4 \mathrm{~B}$ ), for short study duration (correlation $=0.20 ; \mathrm{p}<0.001$; figure $4 \mathrm{C}$ ) and for not paying out-of-pocket costs (correlation $=0.69$; $\mathrm{p}<0.001$; figure 4D). Preferences for medication and CAM compared with lifestyle change were statistically associated with preference for blinding: the correlation with utilities for blinding was $0.28(\mathrm{p}<0.001)$ for utilities for medication over lifestyle change, and $0.36(p<0.001)$ for utilities for CAM over lifestyle change.

\section{Association between individual-level preferences and demographics}

Of the male participants, about $60 \%$ preferred a clinician choosing the treatment (online supplementary table S1 in online supplementary file 3 ) and being involved in conducting the trial (online supplementary table S2), while $53 \%$ were estimated to prefer prescription medication (online supplementary table S3). The preferences among female participants on these attributes were relatively evenly distributed.

Race/ethnicity groups other than non-Hispanic whites were less averse to participation burden (ie, time commitment, data-collection frequency, study duration and out-of-pocket cost) compared with non-Hispanic whites (online supplementary tables S4-S7), although the whole cohort would prefer less burden. 
Table 4 Individual preferences for attributes of Personalised Trials

\begin{tabular}{|c|c|}
\hline Attribute description & $\begin{array}{l}\text { Number of } \\
\text { participants } \\
(\%)\end{array}$ \\
\hline \multicolumn{2}{|l|}{ Treatment selection } \\
\hline Prefer patient choosing treatments & $235(47 \%)$ \\
\hline Prefer clinician choosing treatments & $265(53 \%)$ \\
\hline \multicolumn{2}{|l|}{ Trial conduct } \\
\hline $\begin{array}{l}\text { Prefer no clinician involvement during } \\
\text { study }\end{array}$ & $226(45 \%)$ \\
\hline Prefer clinician involvement during study & $274(55 \%)$ \\
\hline \multicolumn{2}{|l|}{ Treatment types } \\
\hline Prefer prescription medications & $209(42 \%)$ \\
\hline Prefer lifestyle change & $123(25 \%)$ \\
\hline Prefer CAM & $168(34 \%)$ \\
\hline \multicolumn{2}{|l|}{ Patient burden/commitment } \\
\hline 5 min daily & $409(82 \%)$ \\
\hline 30 min daily & $91(18 \%)$ \\
\hline \multicolumn{2}{|l|}{ Data-collection frequency } \\
\hline One time per day & $422(84 \%)$ \\
\hline Three times per day & $78(16 \%)$ \\
\hline \multicolumn{2}{|l|}{ Study duration } \\
\hline 2 weeks & $243(49 \%)$ \\
\hline 12 weeks & $257(51 \%)$ \\
\hline \multicolumn{2}{|l|}{ Out-of-pocket costs } \\
\hline None & $441(88 \%)$ \\
\hline US\$100 & $59(12 \%)$ \\
\hline \multicolumn{2}{|l|}{ Blinding } \\
\hline Prefer not blinding & $352(70 \%)$ \\
\hline Prefer blinding & $148(30 \%)$ \\
\hline
\end{tabular}

CAM, complementary alternative medicine.

Participants younger than 65 years were overall less averse to participation burden than the older group (except for study duration). In addition, the younger participants demonstrated greater variability in their utilities for data collection frequency (variance ratio $=1.32$; $\mathrm{p}=0.040$; figure $5 \mathrm{~A}$ ) and cost (variance ratio $=1.48$; $\mathrm{p}=0.004)$ than the older participants, resulting in some outlying values favouring high burden (figure 5B).

Participants who were employed were less averse to costs (online supplementary table S7) and high frequency of data collection (online supplementary table S5) than those who were unemployed. They also demonstrated greater heterogeneity in their preferences for these attributes with variance ratios $2.07(\mathrm{p}<0.001$; figure $5 \mathrm{C})$ and $1.66(\mathrm{p}<0.001$; figure 5D), respectively. Participants with high income were less averse to bearing some out-ofpocket costs than those with low income (online supplementary table S7), with greater heterogeneity in their
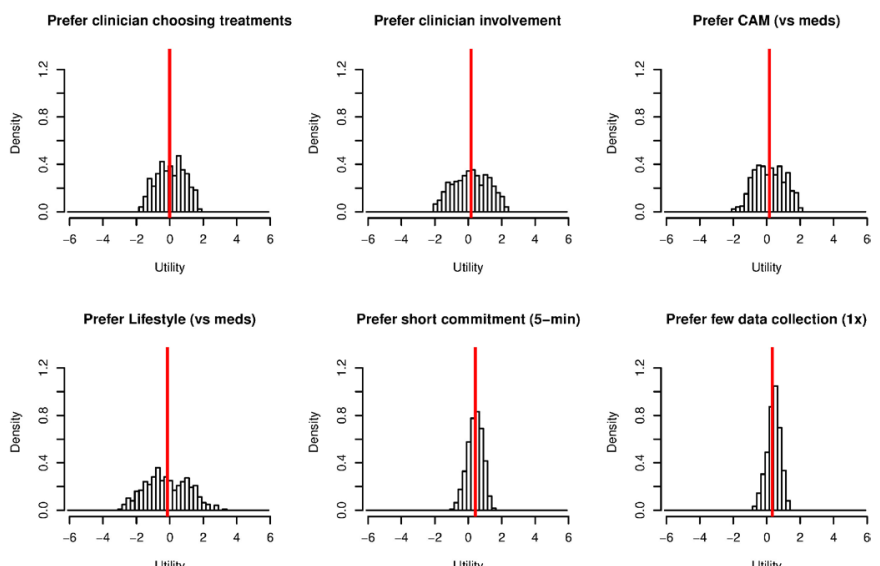

Utility
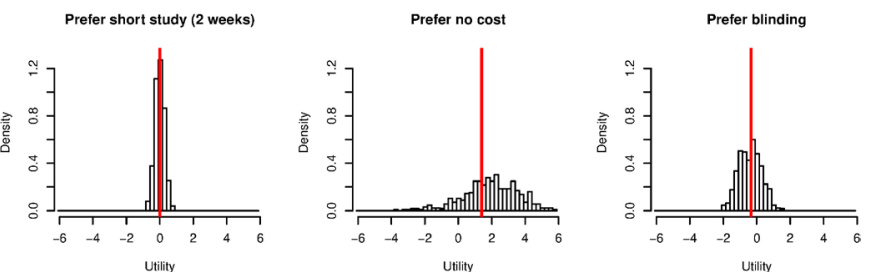

Figure 3 Distribution of individual-level utilities for different attributes. The vertical red lines indicate the average utility in the cohort. CAM, complementary alternative medicine.

preference for high data-collection frequency (variance ratio=1.45; $\mathrm{p}=0.005$; figure $5 \mathrm{E}$ ) and out-of-pocket costs (variance ratio $=1.72 ; \mathrm{p}<0.001$; figure $5 \mathrm{~F}$ ).

Education was associated with treatment types: participants with a college education or more preferred prescription medication, whereas the others preferred CAM (online supplementary table S3).

Insurance status and region of residence did not correlate with any preferences in design attributes. No
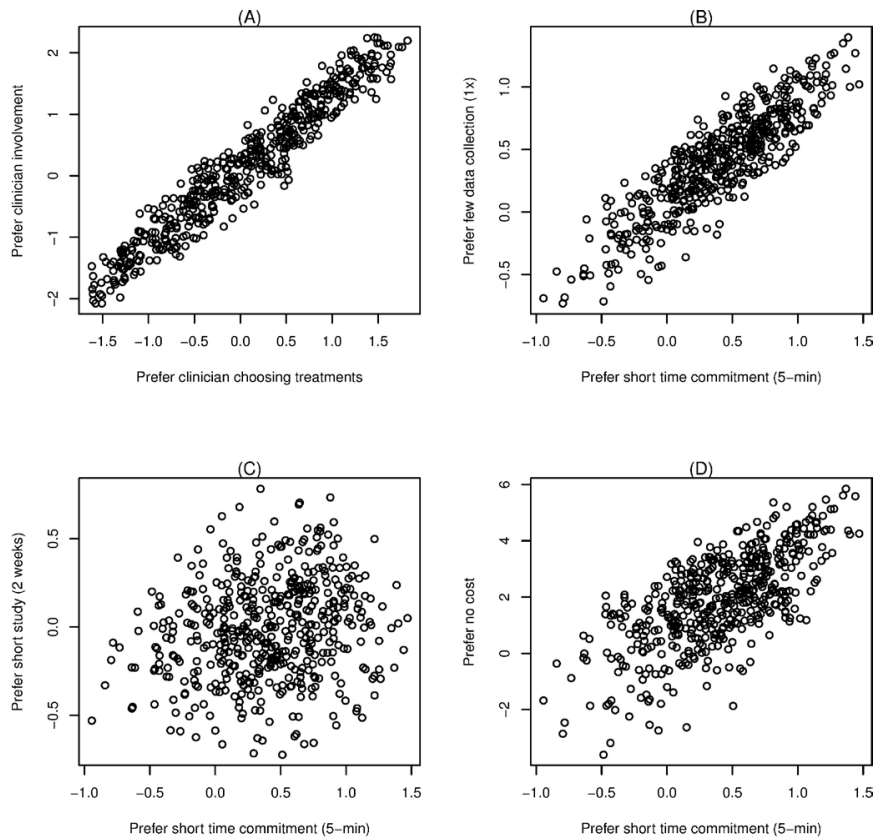

Figure 4 Correlations of individual-level utilities for some attributes. 

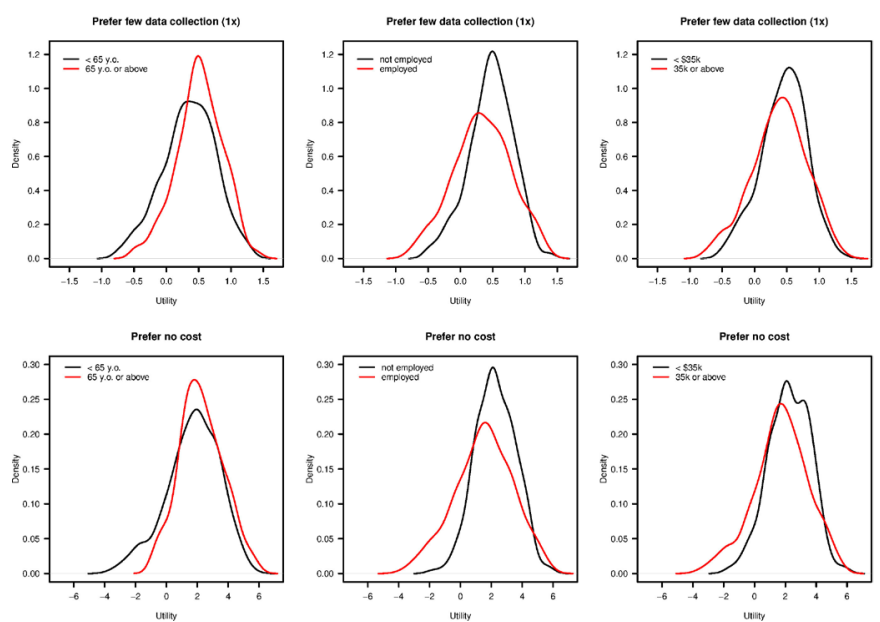

Figure 5 Distribution of individual-level utilities for datacollection frequency (top) and out-of-pocket cost (bottom) by age, employment status and income.

association was found between preference for blinding and any demographics, suggesting blinding was consistently undesirable across the demographic spectrum (online supplementary table S8).

\section{Association between individual-level preferences and chronic conditions}

Patients with diabetes (and to a lesser extent those with hyperlipidaemia) preferred clinician involvement (online supplementary tables S9 and S10). In addition, diabetic patients with interest in Personalised Trials preferred medications compared with the other groups (online supplementary table S11).

Patients with asthma preferred no clinician involvement (online supplementary table S10). They were less averse to participation burden in terms of daily time commitment (online supplementary table S12) and datacollection frequency (online supplementary table S13), although no difference was noted for study duration (online supplementary table S14). A larger percentage of asthma patients preferred out-of-pocket cost compared with other patients (online supplementary table S15). In particular, participants with hypertension were more costsensitive than those with other conditions (online supplementary table S15).

Participants with joint pain or back pain who were interested in participating in a Personalised Trial preferred a long study duration (online supplementary table S14), but were also much less willing to bear costs compared with those without the diagnosis (online supplementary table $\mathrm{S} 15$ ).

None of the patient conditions were correlated with blinding (online supplementary table S16).

\section{DISCUSSION}

In this article, we analysed a conjoint survey conducted in a representative sample of patients with multiple chronic conditions living in the USA and aimed to understand the variability in preferences for design attributes in Personalised Trials. Using empirical Bayesian estimation, we assessed the individual-level utilities of the design attributes in the cohort. We found that the personalised model would improve on prediction of response to participation in Personalised Trials in a population-level model.

\section{Comparison of findings}

Our analysis offers important insights into the heterogeneity in preferences among individuals and suggests the need to personalise design features of Personalised Trials, including attributes that were deemed or thought to be undesirable. For example, while focussing on minimal time commitment and cost may be the best marketing approach based on the population-level analysis, we identified small segments in the cohort that were less averse to out-of-pocket costs (eg, high income, asthma) and long daily time commitment (eg, younger). The implication on practice is even greater for attributes with marked heterogeneity, such as study duration. Because one-half of the cohort preferred a short study duration and the other half preferred long duration, it may be beneficial to market the study duration based on patient preference. Our results also provide trialists of pain studies based on insights that long study trials are generally acceptable and even preferred among patients with chronic joint pain or back pain. Overall, our findings suggest that for those attributes with marked heterogeneity, the best approach may be to allow patients to design their own trials (eg, around treatment options, level of clinician involvement) to maximally improve acceptability and uptake of Personalised Trials.

We also confirmed our previous descriptive analysis and showed that out-of-pocket costs and long daily time commitment were two major deterrents of participation in Personalised Trials when averaged across patients. By using the full conjoint data (short and long questions, not only long questions), we also found additional undesirable attributes. For example, blinding negatively affected interest in participating in Personalised Trials at the population level (table 3 ). Our results are consistent with studies showing that blinding is a strong negative driver of patient decision-making regarding participation in clinical trials. ${ }^{30}{ }^{31}$ On the other hand, our analyses of the individual preferences indicated that almost $30 \%$ of the participants actually preferred blinding as a design feature (table 4). This trend was quite robust across demographics and chronic conditions (online supplementary tables S8 and S16). Thus, our results suggest that providers and researchers may want to design trials in which blinding is optional in order to reach the maximum number of patients. This is particularly true for trials involving lifestyle change where blinding may not be feasible in the first place. Scientific validity in these settings should be further scrutinised by measuring and studying the underlying mechanisms of action (eg, selfefficacy). On the other hand, it is interesting to note that participants who preferred medication or CAM were less 
averse to blinding. Therefore, blinding might still be a feasible choice to explore among patients who chose to test medication and CAM.

\section{Clinical implications}

Personalised Trials are designed to help a patient and his or her clinician make healthcare decisions that are informed by high-integrity, evidence-based information that is uniquely relevant to that patient's preferred outcomes and values. However, in the past, patients have not been willing to engage in these trials. Consequently, this powerful approach is almost never used. Only 108 series of Personalised Trials have been published, ${ }^{15}$ a marked dearth compared with other research methods. Major barriers to implementing Personalised Trials include a lack of knowledge about the conditions, treatments and outcomes for which patients would view such trials as beneficial; lack of design features that have been widely agreed on and would be acceptable to patients considering involvement in a Personalised Trial and poor understanding of patient tolerance for outcome assessment and burden. ${ }^{23} 32$

Our findings support the implementation of Personalised Trials by providing information about the conditions and characteristics associated with greater acceptance of these trials, especially when combined with the use of technology. They also suggest useful strategies for improving uptake in select populations. For example, we found that asthma patients were more open to a greater frequency in data collection during a day, which might be best facilitated by smartphone and mobile technologies that automate daily collection and alleviate the burden on outcome assessments. ${ }^{33-35}$

\section{Strengths, limitations and future research}

Our survey leveraged the panel assembled and maintained by the rigorous Harris Poll Online and was performed in a cohort representative for age, gender, race/ethnicity, socioeconomic status and region of residence in the USA. The 18 questions in the conjoint survey were completely answered in all but four participants, giving reliability in the assessment of individuallevel preference for the eight design attributes, and resulting in new insights beyond our previous report that focussed on design acceptability at a population level. In addition, the empirical Bayesian procedure facilitated borrowing information from across individuals, and yielded stable computational results when estimating the individual utilities. The correlation among utilities for certain attributes and demographic variables demonstrated high level internal consistency.

Despite the strengths in the survey design and conduct, this study has a few limitations. First, the generalisability of our findings might have been limited by the eligibility criteria that included only participants with two or more predefined chronic conditions. In addition, due to the online survey methodology, our sample consisted of those with Internet access and those who could self-report the symptoms of their conditions. However, as we created the list of chronic conditions using a careful process involving focus groups and national survey, these conditions captured the most common and burdensome symptomatic and asymptomatic conditions in the USA. Furthermore, the cohort was sampled to achieve the demographic, geographic and socioeconomic diversity representative of the USA.

Second, the individual-level analysis was performed as an exploratory analysis to describe the heterogeneity in the population. As a result, the number of conjoint questions as well as the survey sample size were not determined a priori to ensure adequate precision in this analysis. Specifically, the sample size would not be adequate to assess the interaction of chronic conditions on preference differences. For example, only 28 participants with asthma and hypertension indicated they were very interested in participation in an asthma Personalised Trial and a hypertension Personalised Trial. Our study data might however suggest the more prevalent comorbidity combinations for further investigation. Third, the attributes and the levels of attributes considered in the survey was not disease specific. As a result, some of the levels might not be ideally defined; for example, 12 weeks might not be considered a long study in the asthma population. Fourth, our analyses were not designed to assess the relationship between attributes and actual behaviour around or acceptance for a Personalised Trial protocol in the survey, as the conjoint choice-based questions aimed to elicit implicit relative utilities for different levels of attributes in the protocol and to identify important attributes for personalisation. While disseminating the results to the online study participants is not applicable, future research should focus on testing whether including these individual preferences in a Personalised Trial design will increase acceptability by the patients and facilitate dissemination and integration into clinical practice.

\section{CONCLUSIONS}

In the true spirit of Personalised Trials, we sought to ascertain individual variability in preferences for the design of Personalised Trials. Incorporating individual preferences may improve willingness to participate in Personalised Trials. Our study also provides a framework for elucidating the degree to which individuallevel (vs population-level) factors drive willingness and behaviour, with widespread implications for improving the uptake of other patient-centred evidence-based innovations and programmes. Just as Personalised Trials are intended to best match patients with effective treatments, understanding individual preferences for Personalised Trials is an equally important consideration for matching the design of a Personalised Trial with a patient's preference. 
Acknowledgements We would like to thank the patient representatives who participated in our collaboratory and the focus groups. Their involvement has provided tremendous insights into the development of the conjoint survey.

Contributors YC drafted the manuscript with inputs from all authors. All authors reviewed the manuscript, made critical comments and approved the final version. KWD and IK were involved in study concept and obtaining funding. YC, DW, TAR, ND, $\mathrm{LD}, \mathrm{KWD}$, IK and NM were involved in the design of the study. DW, TSO and JD-H were involved in data acquisition. YC, DW and KZ were involved in data analysis.

Funding This work was supported by funds from PCORI (ME-1403-12304) and from the NIH/NIMH (R01MH109496).

Competing interests None declared.

Patient and public involvement Patients and/or the public were involved in the design, or conduct, or reporting or dissemination plans of this research. Refer to the Methods section for further details.

Patient consent for publication Not required.

Ethics approval Study procedures and materials were submitted and approved by the Chesapeake Institutional Review Board in February 2017.

Provenance and peer review Not commissioned; externally peer reviewed.

Data availability statement Data are available upon reasonable request by sending an email to the Corresponding author.

Open access This is an open access article distributed in accordance with the Creative Commons Attribution Non Commercial (CC BY-NC 4.0) license, which permits others to distribute, remix, adapt, build upon this work non-commercially, and license their derivative works on different terms, provided the original work is properly cited, appropriate credit is given, any changes made indicated, and the use is non-commercial. See: http://creativecommons.org/licenses/by-nc/4.0/.

\section{ORCID iDs}

Ying Kuen Cheung http://orcid.org/0000-0001-8530-035X

lan Kronish http://orcid.org/0000-0003-0945-2380

\section{REFERENCES}

1 Schork NJ. Personalized medicine: time for one-person trials. Nature 2015;520:609-11.

2 Vohra S. N-of-1 trials to enhance patient outcomes: identifying effective therapies and reducing harms, one patient at a time. J Clin Epidemiol 2016;76:6-8.

3 Duan N, Kravitz RL, Schmid CH. Single-patient (n-of-1) trials: a pragmatic clinical decision methodology for patient-centered comparative effectiveness research. J Clin Epidemiol 2013;66:S21-8.

4 Guyatt G, Jaeschke R. N-of-1 Randomized Controlled Trials: Study Design. In: Guyatt G, Rennie D, eds. Users' guides to the medical literature. 2 edn. New York: McGraw Hill Medical, 2008: 179-92.

5 Guyatt GH, Keller JL, Jaeschke R, et al. The n-of-1 randomized controlled trial: clinical usefulness. our three-year experience. Ann Intern Med 1990;112:293-9.

6 Nikles CJ, Yelland M, Glasziou PP, et al. Do individualized medication effectiveness tests ( $\mathrm{n}$-of- 1 trials) change clinical decisions about which drugs to use for osteoarthritis and chronic pain? Am J Ther 2005;12:92-7.

7 Larson EB. N-of-1 trials: a new future? J Gen Intern Med 2010;25:891-2

8 Joy TR, Monjed A, Zou GY, et al. N-of-1 (single-patient) trials for statin-related myalgia. Ann Intern Med 2014;160:301-310-10.

9 Roustit M, Giai J, Gaget O, et al. On-demand sildenafil as a treatment for Raynaud phenomenon: a series of N-of-1 trials. Ann Intern Med 2018;169:694-703.

10 Kravitz RL, Schmid CH, Marois M, et al. Effect of mobile devicesupported single-patient multi-crossover trials on treatment of chronic musculoskeletal pain: a randomized clinical trial. JAMA Intern Med 2018;178:1368-77.
11 Samuel JP, Tyson JE, Green C, et al. Treating hypertensionn in childrenn With $n$-of-1 trials. Pediatrics 2019;143:e20181818.

12 Kronish IM, Cheung YK, Shimbo D, et al. Increasing the precision of hypertension treatment through personalized trials: a pilot study. $J$ Gen Intern Med 2019;34:839-45.

13 Kravitz RL, Duan N, Niedzinski EJ, et al. What ever happened to nof-1 trials? Insiders' perspectives and a look to the future. Milbank $Q$ 2008;86:533-55.

14 Guyatt G. N of 1 randomized trials: a commentary. J Clin Epidemiol 2016;76:4-5

15 Gabler NB, Duan N, Vohra S, et al. N-of-1 trials in the medical literature: a systematic review. Med Care 2011;49:761-8.

16 Cogburn $\mathrm{DL}$. $\mathrm{HCl}$ in the so-called developing world. Interactions 2003;10:80-7.

17 Moise N, Wood D, Cheung YKK, et al. Patient preferences for personalized ( $\mathrm{n}$-of-1) trials: a conjoint analysis. J Clin Epidemiol 2018;102:12-22.

18 Ryan M, Farrar S. Using conjoint analysis to elicit preferences for health care. BMJ 2000;320:1530-3.

19 Bridges JFP, Hauber AB, Marshall D, et al. Conjoint analysis applications in health--a checklist: a report of the ISPOR good research practices for conjoint analysis task force. Value Health 2011;14:403-13.

20 Phillips KA, Johnson FR, Maddala T. Measuring what people value: a comparison of "attitude" and "preference" surveys. Health Serv Res 2002;37:1659-79.

21 de Bekker-Grob EW, Ryan M, Gerard K. Discrete choice experiments in health economics: a review of the literature. Health Econ 2012;21:145-72.

22 Lee SJ, Newman PA, Comulada WS, et al. Use of conjoint analysis to assess HIV vaccine acceptability: feasibility of an innovation in the assessment of consumer health-care preferences. Int J STD AIDS 2012;23:235-41.

23 Kronish IM, Alcántara C, Duer-Hefele J, et al. Patients and primary care providers identify opportunities for personalized (n-of-1) trials in the mobile health era. J Clin Epidemiol 2017;89:236-7.

24 Shaffer JA, Kronish IM, Falzon L, et al. N-of-1 randomized intervention trials in health psychology: a systematic review and methodology critique. Ann Behav Med 2018;52:731-42.

25 National Center for Health Statistics (US). National center for health statistics (US). health, United States, 2010: with special feature on death and dying. Hyattsville, MD: National Center for Health Statistics, 2011.

26 DeVol R, Bedroussian A, Charuworn A, et al. An unhealthy America: the economic burden of chronic disease charting a new course to save lives and increase productivity and economic growth. Santa Monica, CA: Milken Institute, 2007.

27 Shonkoff ET, Anzman-Frasca S, Lynskey VM, et al. Child and parent perspectives on healthier side dishes and beverages in restaurant kids' meals: results from a national survey in the United States. BMC Public Health 2017;18:56.

28 Blackwell DL, Lucas JW, Clarke TC. Summary health statistics for U.S. adults: national health interview survey, 2012. Vital Health Stat 10 2014:1-161.

29 Bates D, Mächler M, Bolker B, et al. Fitting linear mixed-effects models using Ime4. J Stat Softw 2015;67:1-48.

30 Halpern SD, Karlawish JHT, Casarett D, et al. Hypertensive patients' willingness to participate in placebo-controlled trials: implications for recruitment efficiency. Am Heart J 2003;146:985-92.

31 Sugawara N, Ishioka M, Tsuchimine S, et al. Attitudes toward placebo-controlled clinical trials among depressed patients in Japan. $J$ Affect Disord 2018;225:313-6.

32 Kravitz RL, Duan N. Design and implementation of N-of-1 trials: a user's guide. Rockville, MD: Agency for Healthcare Research and Quality, 2014.

33 Patel MS, Asch DA, Volpp KG. Wearable devices as facilitators, not drivers, of health behavior change. JAMA 2015;313:459-60.

34 Kumar S, Nilsen WJ, Abernethy A, et al. Mobile health technology evaluation: the mHealth evidence workshop. Am J Prev Med 2013;45:228-36.

35 Andrews S, Ellis DA, Shaw $\mathrm{H}$, et al. Beyond self-report: tools to compare estimated and real-world smartphone use. PLoS One 2015;10:e0139004 